\title{
Future-looking conversations in CSCL
}

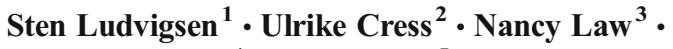 \\ Carolyn P. Rosé ${ }^{4}$. Gerry Stahl ${ }^{5}$
}

Published online: 13 September 2016

(C) International Society of the Learning Sciences, Inc. 2016

In this issue of the journal, we have several new initiatives that we want to promote. The four articles consist of a new review study, a conceptual discussion with critical responses about the concept of scripts in Computer-Supported Collaborative Learning (CSCL), and two articles with new insight about designs for low achievers and learning with epistemic games. We will also share some of the ideas, reflections, and stances in our field from the invited symposium that we organized at the 12th International Conference of the Learning Sciences in Singapore in June. Finally, the journal will launch a new format for contributions called Squibs (see the description at the end of this editorial). The intention with this format is that we as a community can engage in writing shorter contributions that raise awareness of competing theoretical or methodological developments, shortcomings, or new and emerging topics or issues in our field that we should address.

As you see in the list of authors for this editorial, the former president of ISLS and associate editor in this journal, Carolyn P. Rosé, has become one of the executive editors. We warmly welcome her in this position. The expertise that she brings to the

Sten Ludvigsen

Sten@ijCSCL.org

Ulrike Cress

Ulrike@ijCSCL.org

Nancy Law

Nancy@ijCSCL.org

Carolyn P. Rosé

cprose@cs.cmu.edu

1 University of Oslo, Oslo, Norway

2 Knowledge Media Research Center, Tübingen, Germany

3 University of Hong Kong, Hong Kong, China

4 Carnegie Mellon University Language Technologies Institute and HCI Institute, Gates-Hillman Center 5415, 5000 Forbes Ave., Pittsburgh, PA 15213-3891, USA

5 Drexel University, Philadelphia, PA, USA 
editorial team is vital for advancing the CSCL field and this journal, and especially for maintaining disciplinary balance at all levels.

\section{Review studies and integration of lines of research}

The contributions in this issue consist of four original contributions and a response. The journal seeks to increase critical reflections concerning core concepts and approaches, and we think one way of doing this is by inviting responses to papers that address central concepts and approaches in CSCL.

CSCL should now be seen as a mature field, meaning that it is time the community surveys the field at large as well as specific areas within the field (Jeong et al. 2014). Several research groups are working on broad reviews of the CSCL field, and we look forward to seeing these contributions. Reviews can take various forms, such as meta-analysis, systematic reviews, or conceptual reviews. Reviews create new premises and reveal the accumulated knowledge in the field. When technological artifacts change, it is important that the other aspects of CSCL provide us with stable conceptual frameworks in which the technological changes can be integrated.

Another concern that is addressed in current CSCL research involves the interrelatedness or intertwining of different factors or phenomena connected to social, emotional, and cognitive dimensions (Enyedy et al. 2015). In the last issue, Polo et al. (2016) addressed this in an empirical contribution based on two case studies. The teachers' contributions to students' collaborative learning is beginning to receive increased attention (Furberg 2016). In policy and the popular literature about games and gaming, many broad claims have been put forward. For the CSCL field, the studies that investigate epistemic or serious games may be seen as the most interesting (Shaffer 2007). However, relatively few studies so far have described and explained what and how students learn in games. Exceptions do, of course, exist (for an overview, see Clark et al. 2016). In this issue, Brom and colleagues present new insight in learning with games. In the fourth article, Pierre Tchounikine contributes a critical account of CSCL script theory; and Stegman, Kollar, Weinberger, and Fischer contribute a response to this article.

\section{Socially shared self-regulation of learning}

In the first article, "Socially shared regulation of learning in CSCL: Understanding and prompting individual- and group-level shared regulatory activities," authors Järvelä, Kirschner, Hadwin, Järvenoja, Malmberg, Miller, and Laru review CSCL studies in regard to effectiveness and efficacy of cognitive, motivational, emotional, and social issues. The perspective used in the review is socially shared regulation of learning. When students or participants work in CSCL settings, regulation is a major problem that they must address. This regulation is both related to individual capacities and the social dimensions that emerge in group processes. Having self-regulation and collaboration as their starting point, Järvela et al. review designed tools and empirical studies that are supposed to enhance regulation for individuals and groups. This review of empirical studies of tools gives an overview of what the CSCL community has achieved and where we need to intensify our work, or reformulate our assumptions about what works, and under which conditions. This study accomplishes both with a robust review that demonstrates how we can integrate empirical results from different lines of research in CSCL. 


\section{Student achievement varies: how can all students be supported?}

Many CSCL studies show that students and participants vary in their engagement and what they achieve. Both process studies and outcome studies give us interesting accounts about variation (Chen et al. 2015; Damsa 2014; Overdijk et al. 2014). Different approaches contribute to the deepening of our insight into how different tools and support structures help students with varied prior knowledge and experiences. However, most CSCL studies just report on variation as part of their analysis; few studies take variation as a premise and design studies for addressing the problems that low achievers experience. One exception is the study by Slakmon and Schwarz (2014), which directs analytic attention towards disengaged students in how and why they choose to participate in CSCL settings in particular ways.

The second article in this issue, "Reflective assessment in knowledge building by students with low academic achievement," by Yang, van Aalst, Chan, and Tian is a study designed for understanding how one can support low-achieving students. Developing higher-order skills, self-regulation, and critical thinking in knowledge domains and high involvement in collaborative inquiry is usually attributed to high-achieving students. By selecting and designing a study for the students who do not have high scores, the authors are able to investigate how they can support such cohorts of students.

The CSCL environment is based on the principles of knowledge building augmented by a specific design for reflective assessment (Chen et al. 2015). Knowledge building is an important line of research in CSCL. The approach in this study is to support students' capacities to connect knowledge during a trajectory that involves different sources. The reflective assessment is designed so that students can develop metacognitive skills, such as planning, monitoring, and reflecting. The connections of knowledge are related to questions, ideas, and contributions to the knowledge community. These processes involve fact-seeking, exploration, negotiating and synthesizing as well as making simple claims, elaborations, explanations, meta-cognitive questions and statements. In the designed environment, a knowledge-connection analyzer is developed to support the students.

One of the important and interesting results is that the low achievers are able to make use of the knowledge-connection analyzer. Together with the support of the teachers, the students develop higher-order skills that they can use in their school activities. This exploratory study should spark interest in the CSCL community to extend and strengthen our knowledge about the conditions under which such tools work.

\section{Learning with epistemic games}

Epistemic games have become an important line of research in CSCL (Bielaczyc and Ow 2014). Such games raise conceptual challenges for students. These challenges are often connected to specific knowledge domains in the broad areas of math, science, and the social sciences. One can view some game mechanics as translations and transformations of specific concepts and knowledge domains - in other words, interactive representations of these concepts. In the article, "You like it, you learn it: Affectivity and learning in competitive social roleplay gaming," Brom, Šisler, Slussareff, Selmbacherová, and Hlávka problematize some of the assumptions that have been presented and promoted about games and offer findings from a nuanced empirical study. 
The main hypothesis in this study concerns the relationship between affective variables and students' learning outcomes. The groups that participate are exposed to what the authors call moderate competition. Competition is often seen as a problematic issue when students are expected to learn through collaboration. Many proponents of learning with games have argued that since games seem to increase motivation for participants, we should use principles from gaming to enhance learning of a knowledge domain that is part of the curriculum. The term game-based learning can be seen as problematic in itself since it assumes that games lead to learning. Here we prefer to emphasize the learning that is observed during game play, so that the learning itself provides a more appropriate frame of reference to use as an analytic starting point. Within this frame of reference, the collaborative efforts, setting, context, and environment can be understood to influence learning for the individual participants.

The study by Brom et al. is an experimental study involving three groups of students: one group using a computer environment, which includes competitive elements; one group using computers but without competitive elements; and one group using pen and paper. The intervention lasts 1 day $(7 \mathrm{~h})$. The teachers involved were randomly assigned to the groups. The results show that the computer-based intervention was more effective than the pen and paper; however, not all the hypotheses were confirmed. The findings are interesting and suggest directions for design of epistemic games, further studies and possible use of such environments in schools.

\section{Scaffolding, scripts, and scripting}

Scaffolding participants in their learning activities is perhaps the most important mechanism in CSCL. Scaffolding can enhance learning in a number of different areas. It can support specific cognitive operations as well as both self and social regulation. In the learning process, scaffolding implies a cognitive connection between the students and the tool(s). The overall idea is that the scaffolding should help the students extend their individual abilities to succeed when working with tasks that belong to a potential future practice for them. Students can gain support to collaborate in more productive ways, and the knowledge represented in group practices can be displayed in ways that may facilitate individual cognitive development. In CSCL, scaffolding is part of the design that aims to cultivate students' advanced skills and participation in different social practices.

Based on findings from a high number of empirical CSCL studies, one can conclude that students' collaborations do not automatically activate advanced cognitive processes (Fischer et al. 2013). One of the most influential design approaches is the idea of scripted collaboration, which means that students' work is guided by their internal scripts as well as the designed external scripts. The concept of a script goes back to classical studies in cognitive science (Schank and Abelson 1977).

In the CSCL field, Dillenbourg, Fischer, and their colleagues have contributed many studies about scripting and scripts from a variety of design perspectives as well as empirical studies for more than 15 years (e.g., Dillenbourg and Jermann 2002; Fischer et al. 2013). In the article, "Contribution to a theory of CSCL scripts: Taking into account the appropriation of scripts by learners," Pierre Tchounikine contributes a critical account (even as an insider to that area, since he has been one of the influential researchers in the development of scripts in CSCL). Tchounikine argues that we need a better understanding of how students appropriate scripts. When students make use of scripts, they activate perceptual and cognitive operations in order 
to recognize the characteristics of a task and decide how they will participate in it. In addition, he points out that important motivational aspects are missing in the Script Theory of Guidance (SToG model). A script is seen as a resource for action that can be perceived and interpreted differently by students. Tchounikine argues that we need a better understanding of the individual as an entry point for explaining students' use of scripts. The entry point may be called the unit of analysis. In CSCL, the unit of analysis is often what discriminates between different positions and stances, since it has implications for theory, review of studies, methods, and how results are presented. In addition, in the argument against part of the SToG and the understanding of internal scripts, he provides us with alternative analyses of situations and institutional aspects that might influence a situation and the activities. The term "didactical contract" is seen as a way of conceptualizing the external environment and settings in which students learn.

Since this article raises fundamental questions about scripts, we have decided to invite one of the leading groups that has contributed to the development of script theory in CSCL to write a response to Tchounikine's article. In the response called, "Appropriation from a Script Theory of Guidance perspective (SToG): A response to Pierre Tchounikine," Stegman, Kollar, Weinberger, and Fischer argue that they are in agreement with the concept of appropriation used by Tchounikine. Both Tchounikine and the response by Stegman et al. provide us with a nuanced discussion about how we can develop a highly differentiated understanding of internal scripts and at the same time how such scripts are influenced and affected by as well as interact with contextual variables in external settings.

From an editorial perspective, Tchounikine's article and Stegman et al.'s response are important for facilitating a continuing community-wide reflection on this key area of research.

\section{The 12th international conference of the learning sciences: the future of CSCL}

The program chairs of the Learning Sciences Conference invited the editors of the journal to propose a symposium on the theme: The Future of CSCL. We invited senior colleagues in the field that represent contrasting positions and stances in CSCL (Ludvigsen et al. 2016). The goal of the symposium as presented in the conference proceedings (Looi et al. 2016, Vol. 1, pp. 16-22) was to identify trends and possible new and emerging lines of research in CSCL. In this editorial, we highlight a few of the possible future lines of CSCL research that were discussed at the conference.

As a field within the learning sciences, the CSCL community will transform itself as social, cultural, cognitive and technological changes occur. The CSCL community contributes to these developments in various ways, by offering new pedagogical and technological designs, computational tools and deep analysis of how and what people learn. The unique combination of the new possibilities that technologies can offer, and the empirical analyses of what people choose to do together create a kaleidoscope for new scientific insights into people's learning. In the symposium we shared our vision and understanding of new challenges for the CSCL community over the next 10 years.

Heisawn Jeong and Cindy E. Hmelo-Silver contributed an analysis of CSCL research practice from a number of different dimensions including research methods, theoretical frameworks, technology, and outcomes. They examined methodological practices of CSCL research in terms of research design, settings, data sources, and analysis methods as they relate 
to theoretical frameworks. Their analysis reveals that CSCL research consists of four distinct method-theory clusters. In their new and updated analysis of the method-theory clusters over a 10 year period (2005-2014), they also emphasize the role of the ijCSCL journal. Reflections on the methodological and theoretical practices of CSCL can help us to brainstorm how different research traditions can benefit from and complement each other, and what role ijCSCL can play in helping the field to advance in a more integrated manner.

Ulrike Cress contributed a discussion about the replication crisis. The robustness of the results in the social sciences (including psychology, learning science, empirical research) are currently being questioned: Are the results valid? More and more scientists criticize that journals have a tendency to publish only significant results and neglect non-significant ones. As a consequence, whole disciplines may deliver highly biased results, where a randomly found pattern represents more noise than robust regularities. In response, some journals have started to place more value on replication studies. As a community of CSCL researchers, we need to pay attention and discuss which types of studies call for replication. In other words, we must decide in which ways the problem of replication is or is not relevant for ijCSCL, and then find a strategy for dealing with it.

Peter Reimann predicts that we will see a kind of semiotic turn in CSCL, with a focus on materiality; a rising interest in the kind of notional and representational systems that are used when people collaborate in particular practice fields. Semiotics is the study of sign systems, their symbolic as well as physical qualities. The new semiotic turn should focus on artifacts that are representative of people's practices, rather than artifacts designed specifically for the purposes of communication and learning: for instance, the blueprints that building engineers and architects use, the symbol system that musicians use, the specialized document types and codes medical practitioners use. By comparison, it may seem that practice-related artifacts play less of a role in CSCL. Is this appropriate given the nature of our field, or is it an area that needs work?

Manu Kapur and Nikol Rummel argue that we need to consider analysis of how learning unfolds over multiple timescales. CSCL can range from shorter timescale ad-hoc groups (in the order of minutes to hours and days) to longer timescale groups and communities (in the order of weeks to months, or even years). Although there is an increasing trend towards longer timescale studies, it seems that the majority of CSCL research still tend to focus on shorter timescales, leaving important developmental and learning trajectories under-explored. Much as we must continue to explore shorter timescale collaborative dynamics, we need to redouble our efforts towards theorizing, designing, and developing methods of analyzing longer timescale dynamics in CSCL, especially if we want CSCL research to make a significant ecological contribution to theory and practice. A greater focus on these larger timescales will also enable our community to bridge more effectively into Computer-Supported Cooperative Work as a closely related research community.

In her presentation, Nancy Law argues that CSCL researchers need to study collaborative problem solving and knowledge construction in real-world, authentic settings beyond classroom and formal educational settings. There are emerging forms of CSCL that are important in organizations and open collaboration communities that cannot be well understood if we confine our theoretical lens to groups of individuals. Expanding our focus beyond the formal educational contexts will bring exciting new theoretical dimensions into our research, and possibly connect us to communities that we have not considered as closely related before. The question she poses is: What is the scope of collaborative learning that our community would wish to define for ourselves? Do we consider the examples of collaboration outside of the 
formal classroom as CSCL? Law argues that non-group based CSCL studies can be viewed as different forms of network-based learning. Many of us in the CSCL community see teacher collaborative learning as crucial to bringing about change in pedagogical practice in the classroom. However, effective teacher learning cannot be brought about through groupbased collaboration alone, and is much better effected through innovation networks.

In the symposium summary, the first author of this editorial ( Ludvigsen) emphasized the following future areas:

- New theoretical challenges. The main issue concerns how we should conceptualize and analyze collaborative learning. This is related to the micro-, meso-, and macro-dimensions of collaboration in specific situations and over longer time periods. The problem of timescales and how they can be analytically connected is emerging as a challenge that needs more attention.

- New methodological challenges. This challenge is closely related to the theoretical challenge. Most CSCL studies deal with rather short timespans, while new methods and techniques make it possible to follow students/people for longer periods. We can say that collaboration is distributed in time, space, and across organizations. In psychology and the social sciences, longitudinal studies with a mix of data sources are now used. The research design that we now use will need to be critically examined in order for us to develop new research designs that can create more valid results.

- The landscape of new technologies and infrastructures. MOOCs and other environments make it possible to collect huge amounts of data. To connect such data in order to understand collaborative learning is still a challenge. Collaborative learning is the focus of CSCL studies. The question becomes how different data sources and analyses can give us new insights about this phenomenon.

- Semiotics or meaning-making will have to take new forms in the future. The artifacts that are used in education and in professional work are becoming more and more advanced. In schools, increasingly advanced statistics, simulations of abstract phenomena, and visualizations have become part of everyday education in many countries. The knowledge inscribed in these artifacts needs to be understood and articulated by users collaborating with these artifacts. What new practices are required for creating, representing and sharing meaning associated with sophisticated and complex artifacts?

- The last challenge that we put forward here concerns 21 st-century skills and deep learning. The CSCL community can and will contribute with models for learning that can show how such learning can take place in different domains and settings. The question here becomes: How can such efforts be part of the evidence chain that leads to new educational policies?

\section{Squibs: new forms of brief submissions}

While the mainstay of ijCSCL has been full journal-length papers with substantial elaborations of theoretical frameworks, we are introducing a new genre of submissions that we hope will be effective in sparking reflection, discussion, and growth in the field. We call this new genre of submission a Squib, in the tradition of the Computational Linguistics Journal, where this genre was first created. This genre of submission may include short articles reporting technical advancements, brief discussions of thought-provoking findings, cutting-edge algorithms, or new data or tools of interest to the journal readership. These articles may also be focused on 
raising awareness to an emerging trend, a proposed change in practices within the field, or debates on theoretical and/or methodological issues. The contributions of these articles are meant to be positioned on the edges of the field, challenging our boundaries and our thinking. The shorter format is meant to facilitate quicker turnaround time, and thus provide a means for timely discussions in the field. Squib submissions should generally not exceed 3000 words.

\section{References}

Bielaczyc, K., \& Ow, J. (2014). Multi-player epistemic games: Guiding the enactment of classroom knowledgebuilding communities. International Journal of Computer-Supported Collaborative Learning, 9(1), 33-62.

Chen, B., Scardamalia, M., \& Bereiter, C. (2015). Advancing knowledge-building discourse through judgments of promising ideas. International Journal of Computer-Supported Collaborative Learning, 10(4), 345-366.

Clark, D. B., Tanner-Smith, E. E., \& Killingsworth, S. S. (2016). Digital games, design, and learning: A systematic review and meta-analysis. Review of Educational Research, 20(10), 1-44. doi:10.3102 $/ 0034654315582065$.

Damsa, C. I. (2014). The multi-layered nature of small-group learning: Productive interactions in object-oriented collaboration. International Journal of Computer-Supported Collaborative Learning, 9(3), 247-281.

Dillenbourg, P., \& Jermann, P. (2002). Designing integrative scripts. In F. Fischer, I. Kollar, H. Mandl, \& J. M. Haake (Eds.), Scripting computer-supported collaborative learning: Cognitive, computational, and educational perspectives (pp. 275-301). New York: Springer. 2007.

Enyedy, N., Danish, J. A., \& DeLiema, D. (2015). Constructing liminal blends in a collaborative augmentedreality learning environment. International Journal of Computer-Supported Collaborative Learning, 10(1), 7-34.

Fischer, F., Kollar, I., Stegmann, K., \& Wecker, C. (2013). Toward a script theory of guidance in computersupported collaborative learning. Educational Psychologist, 48(1), 56-66.

Furberg, A. (2016). Teacher support in computer-supported lab work: Bridging the gap between lab experiments and students' conceptual understanding. International Journal of Computer-Supported Collaborative Learning, 11, 89-113.

Jeong, H., Hmelo-Silver, C. E., \& Yu, Y. (2014). An examination of CSCL methodological practices and the influence of theoretical frameworks 2005-2009. International Journal of Computer-Supported Collaborative Learning, 9(3), 305-334.

Looi, C. K., Polman, J. L., Cress, U., \& Reimann, P. (Eds.). (2016). Transforming learning, empowering learners: The International Conference of the Learning Sciences (ICLS) 2016, Volume 1. Singapore: International Society of the Learning Sciences.

Ludvigsen, S., Jeong, H., Hmelo-Silver, C., Cress, U., Reiman, P., Kapur, M., Rummel, N., \& Law, N. (2016). In C. K. Looi, J. L. Polman, U. Cress, \& P. Reimann (Eds.). Transforming learning, empowering learners: The International Conference of the Learning Sciences (ICLS) 2016, Volume 1, 16-22. Singapore: International Society of the Learning Sciences.

Overdijk, M., van Diggelen, W., Andriessen, J., \& Kirschner, P. A. (2014). How to bring a technical artifact into use: A micro-developmental perspective. International Journal of Computer-Supported Collaborative Learning, 9(3), 283-303.

Polo, C., Lund, K., Plantin, C., \& Niccolai, G. P. (2016). Group emotions: the social and cognitive functions of emotions in argumentation. International Journal of Computer-Supported Collaborative Learning, 11(2), $123-156$.

Shaffer, D.W. (2007). How computer games help children learn. New York, NY: Palgrave.

Schank, R. C., \& Abelson, R. P. (1977). Scripts, plans, goals and understanding. Hillsdale: Erlbaum.

Slakmon, B., \& Schwarz, B. B. (2014). Disengaged students and dialogic learning: The role of CSCL affordances. International Journal of Computer-Supported Collaborative Learning, 9(2), 157-183. 